\title{
Modelling the Fireballs from Methane Releases
}

\author{
G.M. MAKHVILADZE, J.P. ROBERTS and S.E. YAKUSH \\ Centre for Research in Fire and Explosion Studies \\ University of Central Lancashire \\ Preston PR1 2HE, UK
}

\begin{abstract}
Fireballs occurring on ignition of accidentally released fuel present a major danger because of emission of strong heat radiation. Assessment of the fireball parameters is important for fire safety and risk analysis. In this paper a numerical model for the burning of a methane cloud released into the atmosphere is presented. The internal structure of the fireball arising upon ignition of the release is revealed and the main stages of burning are discussed.
\end{abstract}

KEYWORDS : External fires, fire safety, fireball, modelling

\section{INTRODUCTION}

Accidental release of flammable substances into the atmosphere is one of the major factors of danger in modern industry. Ignition of such a cloud can lead to its explosion accompanied by generation of blast waves, or to a fire with emission of strong heat radiation [1-3]. Major accidents, such as those in Flixborough (1974, UK) and Ufa (1989, Russia) are examples of how dangerous the releases of hydrocarbons into the atmosphere are. The latter accident showed the extreme hazards of large open hydrocarbon fires that can cause numerous casualties.

The studies of combustion of fuel clouds that have been carried out up to now, are mostly experimental (see review in $[1,4]$ ). One of the main results of these studies is the development of phenomenological models for predicting the gross (integral) characteristics of fireballs (duration and size) as functions of the fuel mass released [5]. Theoretical studies of burning clouds were mainly concentrated on dimensional analysis of the problem and development of simple analytical models in which the fireball was approximated by a rising sphere (e.g., [6-8]). Despite its importance, rigorous theoretical study of combustion in fuel clouds has not been performed yet [1]. An attempt to simulate a burning LNG cloud was undertaken in [9], though the assumptions made in description of initial cloud 
shape (idealized "pancake-shaped" cloud) and use of a rather simplistic combustion model restrict the general applicability of the results obtained.

Clearly there is a strong need for the development of models for fireballs that could reveal the internal structure of the burning cloud taking into account the substantial time-dependence of the processes, effect of finite duration of the release, interaction of inertial and buoyant forces, heat release in chemical reactions proceeding in the turbulent mixture and emission of thermal radiation. Such models would not only enhance the understanding of the processes governing the behaviour and evolution of the burning cloud but also provide a useful tool for development and validation of engineering methods suitable for the fire risk analysis. In the current paper the numerical modelling of a fireball arising from release of methane into the atmosphere is presented.

\section{STATEMENT OF THE PROBLEM}

We consider a release of flammable gas into the atmosphere proceeding for some finite time $t_{r}$. A general analysis of such releases has been performed in [10]. It was shown that depending on the relationship between the release time $t_{r}$ and the characteristic turbulent mixing time $t_{m i x}$ the concentration distribution resulting from the release can be similar to that in an instantaneously released cloud $\left(t_{r} \ll t_{m i x}\right)$, to a steady-state jet $\left(t_{r} \gg t_{m i x}\right)$ or to a starting jet in the intermediate case. Ignition of the escaping gas can lead to formation of a burning cloud (fireball) or to a jet fire depending on the type of the release and the ignition delay. A quantitative criterion for classification of the finite-duration gas releases into instantaneous, continuous and intermediate types was offered.

The initial conditions are sketched in Fig. 1. The source of diameter $d$ is located on the ground level, it supplies the fuel gas at a constant rate during the time $t_{r}$ after which the release rate abruptly drops to zero. The source diameter was taken so that the ratio of the diameter to the cubic root of the initial gas volume $\delta=d / V_{0}^{1 / 3}$ is chosen to be equal to 0.3 for all $V_{0}$ considered. It was shown in [10] that this value for $\delta$ corresponds to a "cloud-like" (i.e., finite-duration) release. The release velocity is directed vertically upward, its radial distribution at the source orifice is Gaussian with the width chosen to obtain the correct discharge coefficient $C_{d}=0.85$. The ignition occurs near the source at the axis of symmetry, straight after beginning of the release.

We consider here combustion of a compact fuel cloud originating from a small-size source. Fireballs from such clouds rapidly assume almost spherical shape, that is why only axisymmetric flows are calculated. It should be noted that the study of asymmetric ignition is important in the case fuel cloud explosion, as the parameters of blast waves can depend significantly upon the location of ignition point. Also, asymmetric ignition would be important for pancake-shaped clouds, which are not considered in this paper. A system of time-dependent Favre-averaged Navier-stokes equations for the multicomponent chemically reacting gas is solved numerically in cylindrical coordinates $(r, z)$. Since for deflagration the flow is essentially subsonic, the equations were reduced to an asymptotic form in which the speed of sound is infinite and all sound waves are "filtered out" [13]. This simplification allows the stiffness associated with propagation of sound waves to be removed from the equations, retaining at the same time all physically meaningful factors. 
Species equations are solved for the following chemical components: $\mathrm{O}_{2}, \mathrm{~N}_{2}, \mathrm{H}_{2} \mathrm{O}, \mathrm{CO}_{2}$ as well as for the fuel. The fuel used in calculation is methane $\mathrm{CH}_{4}$, the combustion reaction for which is $\mathrm{CH}_{4}+2 \mathrm{O}_{2} \rightarrow \mathrm{CO}_{2}+2 \mathrm{H}_{2} \mathrm{O}$. The standard $k-\varepsilon$ model of turbulence was used to close the system of equations. The combustion rate is described by the eddy break-up model [11] that is known to give quite acceptable results for both premixed and diffusion flames. A more complex combustion model (e.g., laminar flamelet model) allowing for the complex kinetics of $\mathrm{CH}_{4}$-air reaction and taking into account effect of strain rate, would be essential for description of ignition process and for determination of ignition criteria. Such study, however, was outside the scope of the current paper. Temperature dependencies of the enthalpies and heat capacities of individual species were taken into account, the data on these was taken from [12].

\section{NUMERICAL ASPECTS}

The system of governing equations was solved using the pressure correction technique as described in [14]. In the small Mach number approximation it is assumed that the pressure deviation from the ambient pressure (proportional to the square of the Mach number) is small and it can be neglected in all terms except the pressure gradient in the momentum equation. Thus, the density can be calculated from the temperature and concentration fields and instead of the continuity equation a Poisson equation for the pressure correction has to be solved. All transport equations were approximated implicitly with the first order of accuracy in time and the second order in space, the parabolic scheme was applied to maintain the monotonic behaviour of the solution [15]. The TDMA algorithm was used for solving the resulting algebraic equations, while the Poisson equation for the pressure correction was solved using the successive line overrelaxation method. The computer code is written in $\mathrm{C} / \mathrm{C}++$. Numerous validation tests were performed including calculation of plane free and wall jets, axisymmetric jets and buoyant thermals. The calculations presented below were made using non-uniform grids containing $100 \times 200$ nodes. A typical run on SGI Indigo ${ }^{2}$ workstation takes about $5 \mathrm{hrs}$ CPU time.

Combustion was initiated in the calculations by setting the temperature and species concentrations to those of products of complete methane-air reaction within several grid cells to form a hot "kernel" located several orifice diameters above the ground, and the ignition was triggered when the upper front of the methane cloud reached this point. As numerical experiments had shown, this was enough to ignite the cloud and the further evolution of the fireball did not depend any noticeably upon the details of the ignition. Typically, the ignition occured on several first time steps so that the total combustion time was much longer than the pre-ignition time.

\section{RESULTS}

The results obtained for the releases of $V_{0}=10,100,1000$ and $10,000 \mathrm{~m}^{3}$ of methane are presented. The initial velocity of the release in all cases was taken as $U_{r}=50 \mathrm{~m} / \mathrm{s}$, which corresponds to the releases driven by the overpressure $\Delta P \approx \rho_{f} U_{r}^{2} / 2=8.4$ mbar where $\rho_{f}=0.67 \mathrm{~kg} / \mathrm{m}^{3}$ is the methane density. Further evolution of the burning gas is governed by two main forces - namely, by its inertia and buoyancy. Since the release velocity was 


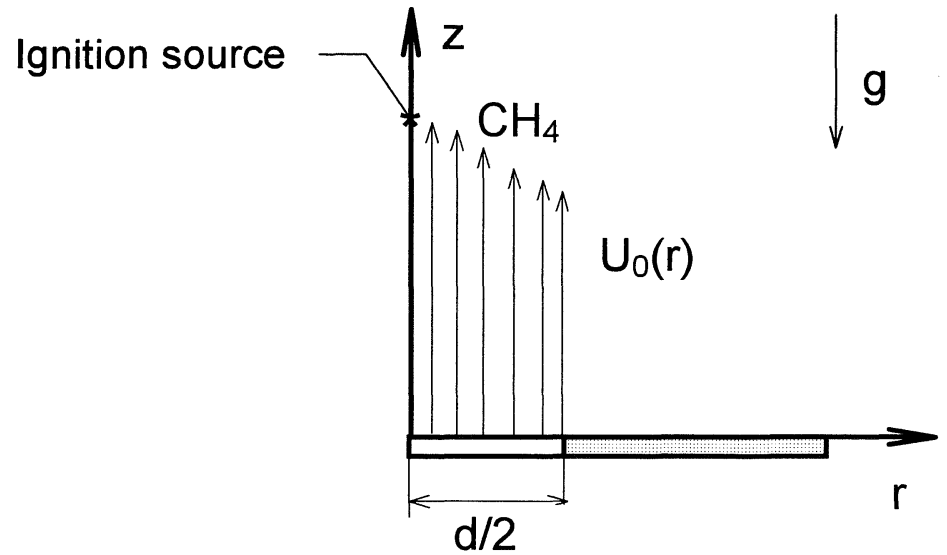

FIGURE 1. Initial conditions used for calculation of finite-duration methane releases

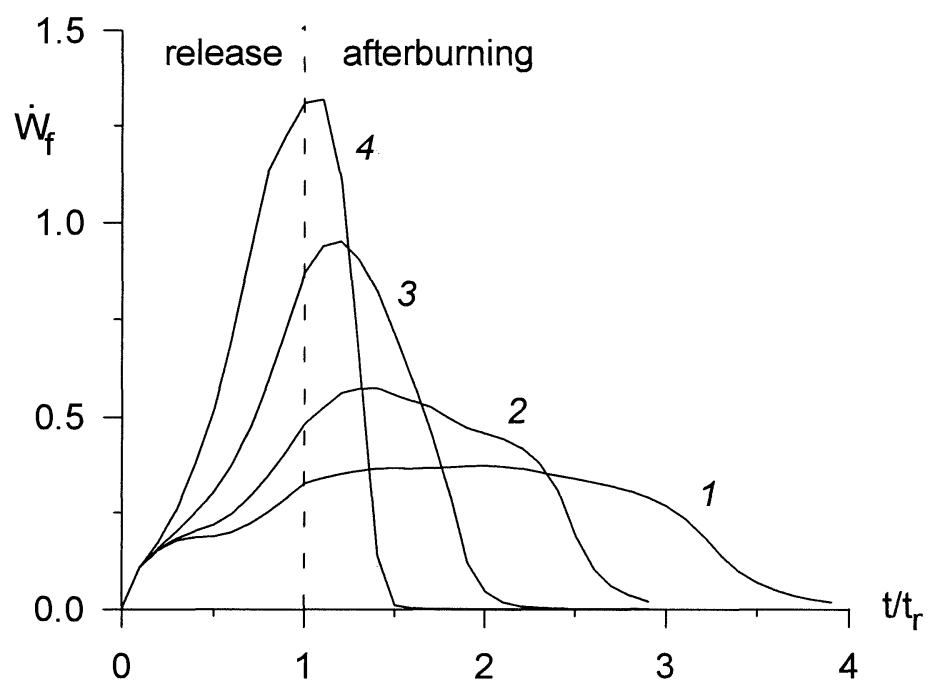

FIGURE 2. Total mass burning rates for different volumes of methane released: 1 $10 \mathrm{~m}^{3}, 2-100 \mathrm{~m}^{3}, 3-1000 \mathrm{~m}^{3}, 4-10,000 \mathrm{~m}^{3}$ 
taken to be constant while the characteristic buoyancy-generated velocity increases as a square root of the cloud size, comparison of the burning histories for various clouds can reveal the relative role of the above processes.

In Fig. 2 the calculated temporal dependencies for the total burning rates are presented in non-dimensional coordinates for the four gas volumes. The time $t$ on the abscissa axis is related to the release time $t_{r}$ while the ordinate $\dot{W}_{f}$ represents the non-dimensional total mass reaction rate defined as $\dot{W}_{f}=\frac{t_{r}}{\rho_{f} V_{0}} \int_{0}^{\infty} \int_{0}^{\infty} \dot{w}_{f} r d r d z$, where $\dot{w}_{f}$ is the local mass fuel consumption rate (note that the total area under the curve $\dot{W}_{f}\left(t / t_{r}\right)$ is unity). Curves 1-4 correspond to the released gas volumes $V_{0}=10,10^{2}, 10^{3}$ and $10^{4} \mathrm{~m}^{3}$. It can be seen that with increase in the initial gas volume the ratio of the burning time to the release time decreases. This is attributed to the increasing role of the buoyancy forces which enhance the mixing of the fuel with ambient air and thus promote the burning. For the smaller gas volumes (e.g., for $V_{0}=10 \mathrm{~m}^{3}$ ) the release is followed by quite long fuel afterburning: in fact, $80 \%$ of the fuel burns in the atmosphere after the release has been terminated. On the other hand, for large gas releases (e.g., for $V_{0}=10^{4} \mathrm{~m}^{3}$ ) the burning time becomes comparable or even less than the release time. In this case more than half of the fuel burns during the release time.

The evolution of the burning cloud is revealed in Fig. 3 - 10 where the internal structure of the cloud at six sequential moments is presented. The initial volume of methane is $V_{0}$ $=10 \mathrm{~m}^{3}$ (the fuel mass $M=6.7 \mathrm{~kg}$ ), the opening diameter $d=0.3 V_{0}^{1 / 3}=0.65 \mathrm{~m}$, the release time $t_{r}=V_{0} /\left(C_{d} \pi d^{2} / 4\right) U_{r}=0.72 \mathrm{~s}$. In each figure the distributions of volume concentrations of fuel (left) and product $\mathrm{CO}_{2}$ are shown together with the distributions of the gas temperature $T$. For each variable 10 gray scale levels between the maximum and minimum values are shown, the relative values corresponding to each gray level are indicated in the right part of the picture. The maximum and minimum values of each variable are shown in the corresponding figures.

Fig. 3 shows the internal structure of the burning release at the moment corresponding to half of the release time $(t=0.36 \mathrm{~s})$. By this time the flame configuration resembles that in a burning jet, the difference, though, is that the release proceeds for a finite time only and the burning is transient in its nature. The radial distributions of species concentrations and temperature in the cross-section $z=2 \mathrm{~m}$ are presented in Fig. 4 . The most intensive burning proceeds in the mixing layer at the periphery of the fuel jet. In this area the fuel mixes with the air to form the combustible mixture. The reaction zone divides the fuelrich and oxygen-rich zones. In general, the structure of the reaction zone is similar to that in the classical diffusion flame. In Fig. 5 the spatial distributions of the same quantities are presented at $t=t_{r}$, i.e., at the time of outflow termination. Combustion still proceeds in the quite narrow layer at the periphery of the jet. By this time approximately $20 \%$ of fuel has been burnt. The release is dominated by momentum created by the source. Radial distributions of concentrations, temperature and reaction rate at $z=3.6 \mathrm{~m}$ are shown in Fig. 6.

Straight after the release termination the structure of the burning jet begins to change. In fact, further evolution of the gas injected into the atmosphere is governed not only by its initial momentum but also by its buoyancy. In Fig. 7 the structure of the cloud 


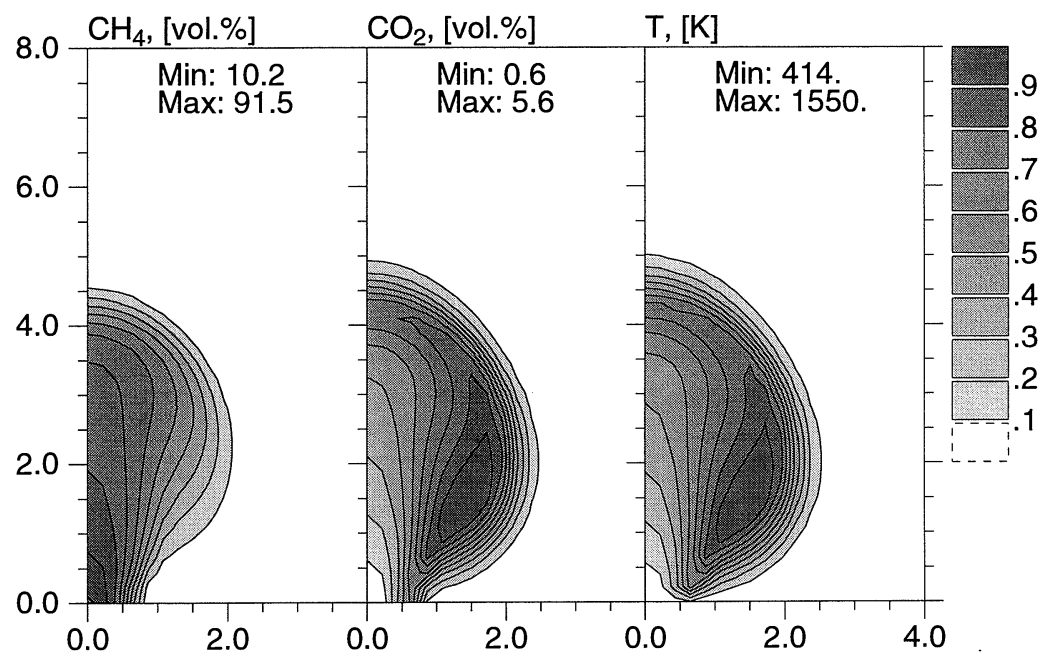

FIGURE 3. Stucture of the burning release at $t=t_{r} / 2(0.36 \mathrm{~s})$

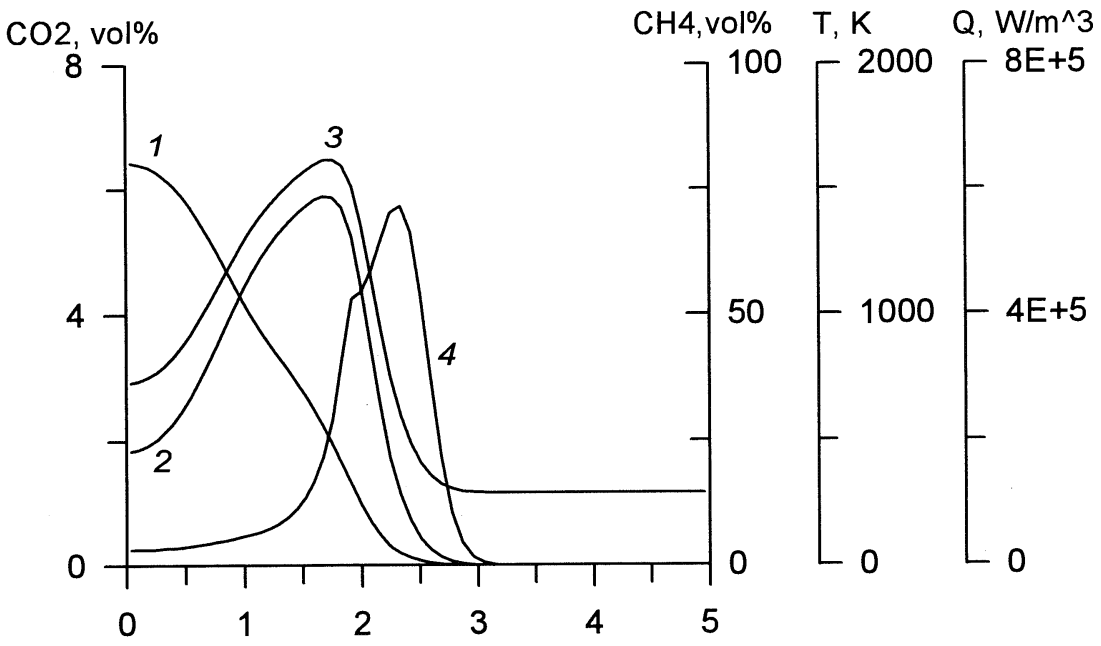

FIGURE 4. Radial profiles in the horizontal cross-section $z=2 \mathrm{~m}$ at $t=t_{r} / 2(0.36 \mathrm{~s})$. 1,2 - volume fractions of methane and carbon dioxide, 3 - temperature, 4 - heat release rate 


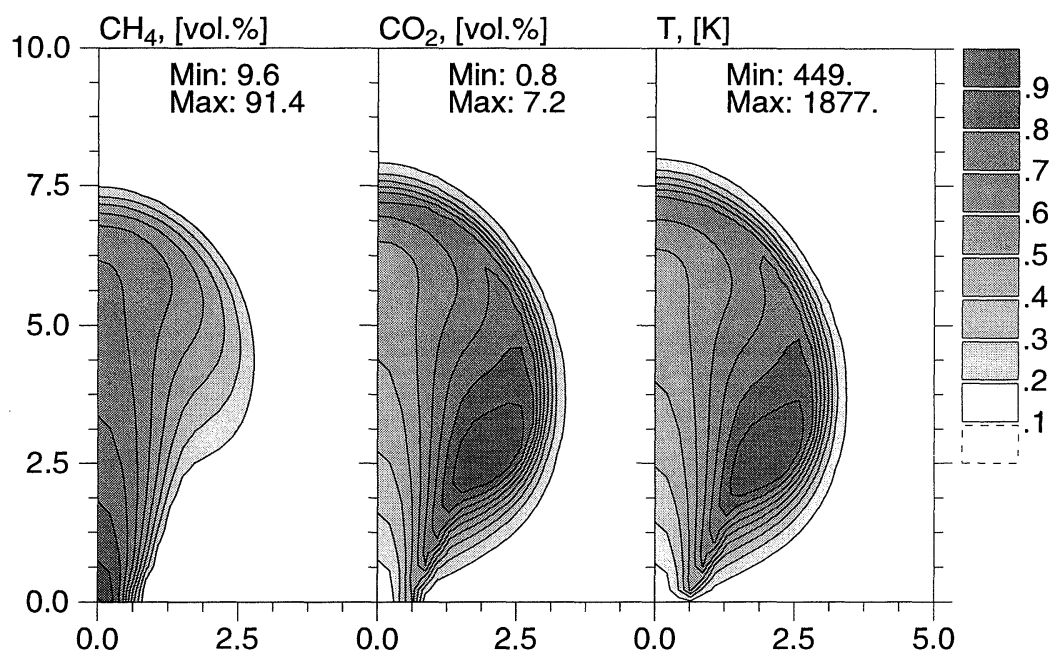

FIGURE 5. Stucture of the burning release at $t=t_{r}(0.72 \mathrm{~s})$

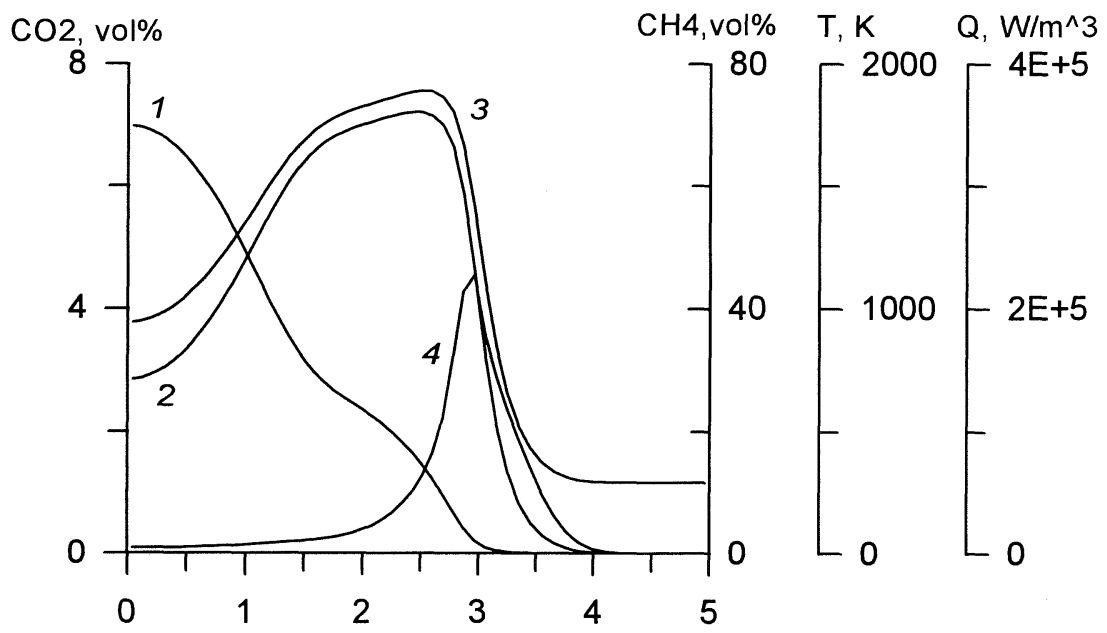

FIGURE 6. Radial profiles in the horizontal cross-section $z=3.6 \mathrm{~m}$ at $t=t_{r}(0.72 \mathrm{~s})$. 1,2 - volume fractions of methane and carbon dioxide, 3 -temperature, 4 - heat release rate 
is shown at $t=1.25 t_{r}=0.9 \mathrm{~s}$, by this time $25 \%$ of fuel has been burnt. The burning release assumes the characteristic "mushroom-like" shape and in its further evolution it can be regarded as a burning cloud or fireball. At the moment $t=1.5 t_{r}=1.08 \mathrm{~s}$ a compact burning cloud is clearly seen in Fig. 8 , by this time $33 \%$ of fuel was consumed. A thin burning stem can still be seen beneath the fireball. This stem disappears later and the fireball seems as detached from the ground. The structure of the fireball at two late moments of its evolution is presented in Fig. $9\left(t=2 t_{r}=1.44 \mathrm{~s}, 50 \%\right.$ of fuel has been consumed) and Fig. $10\left(t=3.5 t_{r}=2.5 \mathrm{~s}, 95 \%\right.$ of fuel has been consumed).

The time histories of the mass of fuel $M_{f}(t)$ and the maximum temperature $T_{m}(t)$ are presented in Fig. 11. The dashed line shows the amount of fuel released into the atmosphere by the time $t$. It can be seen that the fuel gets completely consumed by the moment $t=4 t_{r}=2.9 \mathrm{~s}$ after which a cloud of hot products remains in the atmosphere. After the reaction stops, the temperature quickly falls down because of entrainment of ambient air. Further evolution of the cloud is governed by the relationships relevant to thermals. It may be of interest, e.g., if pollution of the atmosphere by explosion products is studied. An example of numerical simulation of a thermal and of transport of gaseous and dusty pollutants by a rising thermal can be found in $[17,18]$.

Since no experimental work revealing the internal structure of the fireball is known to the authors, the comparisons with the experimental data were performed using the empirical relationships between the diameter and persistence time and the total mass of fuel involved. The formulas given in [5] are

$$
D_{F B}=5.8 M^{1 / 3}, \quad t_{F B}=0.45 M^{1 / 3}
$$

Substitution of the fuel mass of $M=6.7 \mathrm{~kg}$ gives the diameter $D_{F B}=10.9 \mathrm{~m}$ and the burning time $t_{F B}=0.9 \mathrm{~s}$. The data from our calculation gave $D_{F B}=12 \mathrm{~m}$ and $t_{F B}=$ $3.5 t_{r}=2.5 \mathrm{~s}$. A good agreement is evident for the fireball size and much worse for the burning time. The reason for this disagreement can be attributed to a large scatter in the experimental data, studied in detail in [16]. In this work burning of propane and methane releases was investigated and formulas taking into account the initial release velocity were presented. Namely, for a circular orifice the following correlation between the burning time and the release velocity was offered:

$$
t_{F B}^{*}=\frac{10.6}{1+V_{*} / 50}, \quad \text { where } \quad t_{F B}^{*}=t_{F B} g^{1 / 2}\left(\frac{\rho_{0}}{M}\right)^{1 / 6}, \quad V_{*}=V_{r} g^{-1 / 2}\left(\frac{\rho_{0}}{M}\right)^{1 / 6}
$$

(here $\rho_{0}$ is the air density). Substituting our values for $M$ and $V_{r}$ we have found the burning time $t_{r}=3.6 \mathrm{~s}$ which is four times higher that the values given by [5]. We note that our value for the burning time lies between the two above times. We can conclude that the numerical calculation gave quite reasonable predictions for both size and duration of the fireball. We also have to keep in mind that the time during which a visible firiball exists can be longer that the time during which actual chemical reaction proceeds: even after the reaction stops, the hot products still can emit visible light as long as their temperature is high enough. To describe this process more precisely, the radiation heat transfer has to be taken into account. Such model is also essential for modelling the heat radiation impact of the burning cloud on the environment. 


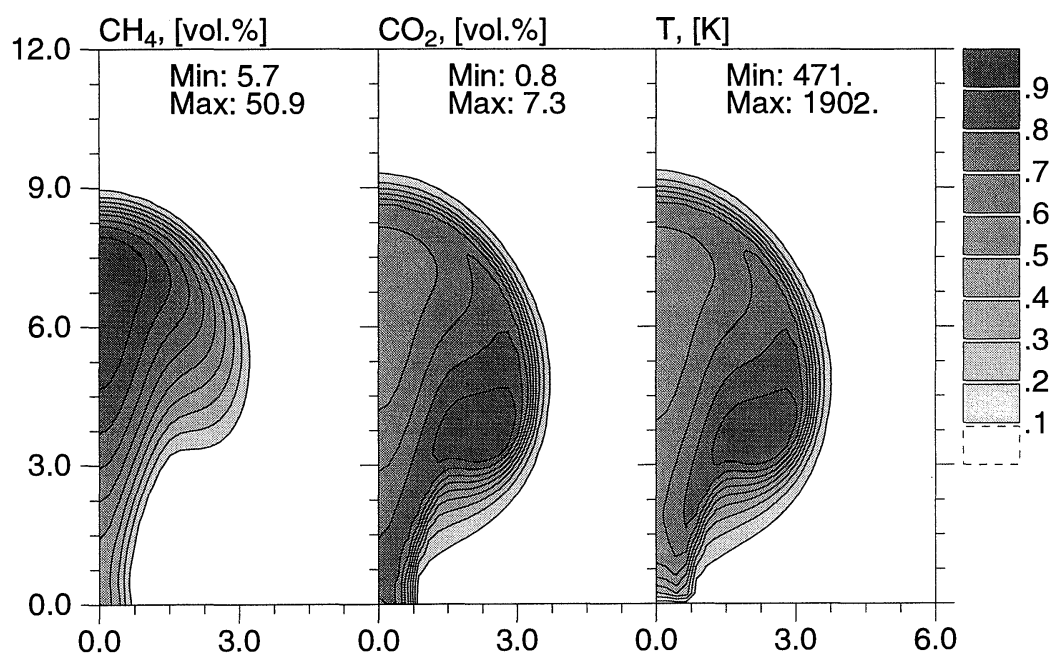

FIGURE 7. Stucture of the burning release at $t=1.25 t_{r}(0.9 \mathrm{~s})$

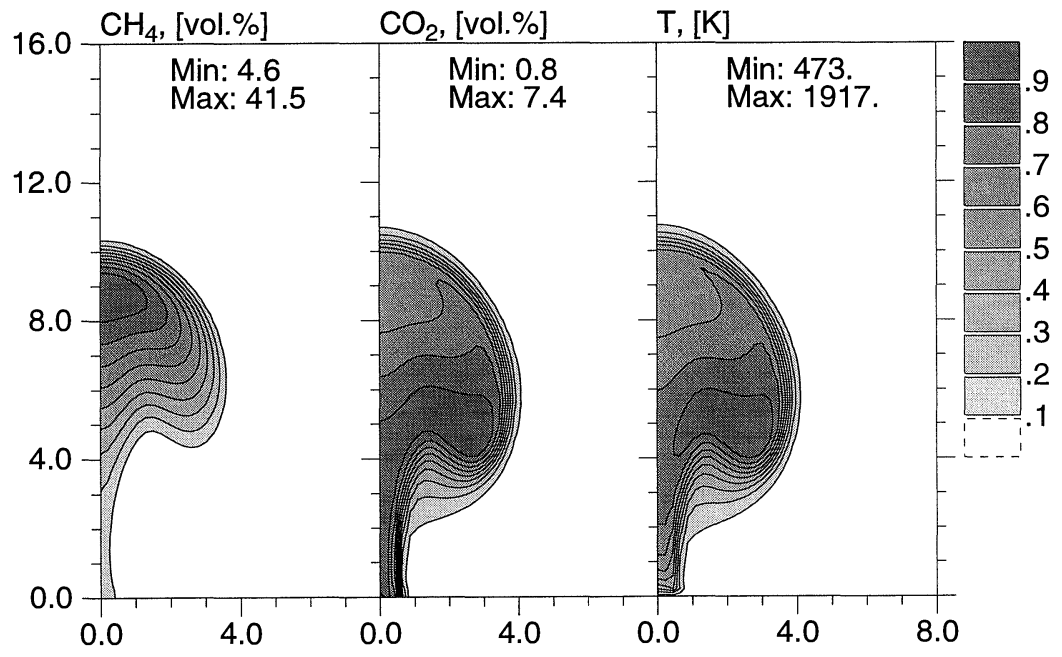

FIGURE 8. Stucture of the burning release at $t=1.5 t_{r}(1.08 \mathrm{~s})$ 


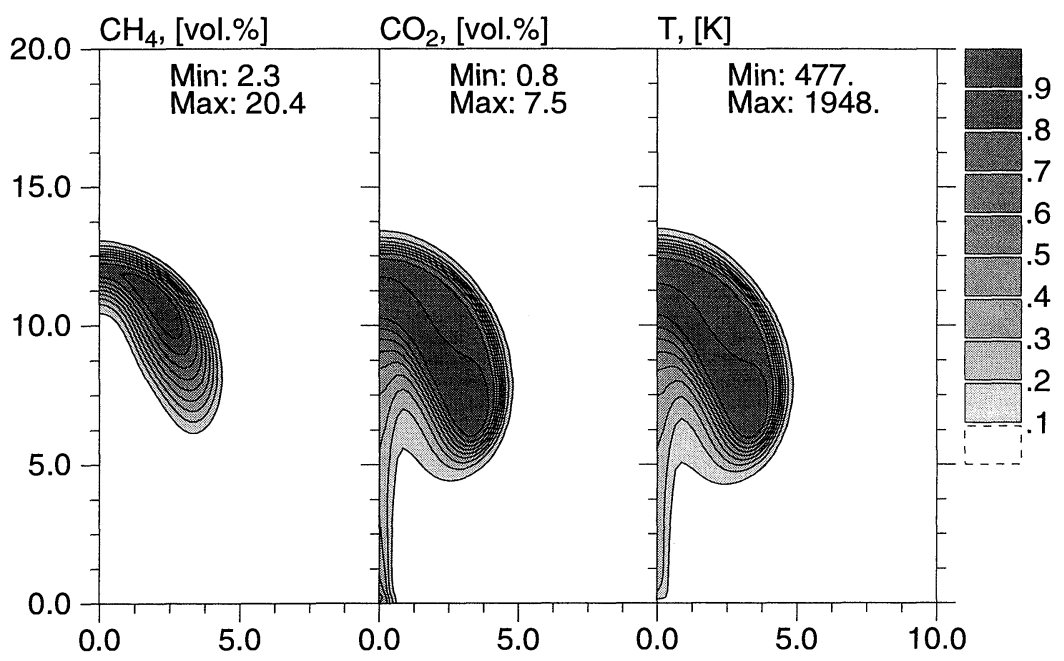

FIGURE 9. Stucture of the burning release at $t=2 t_{r}(1.44 \mathrm{~s})$

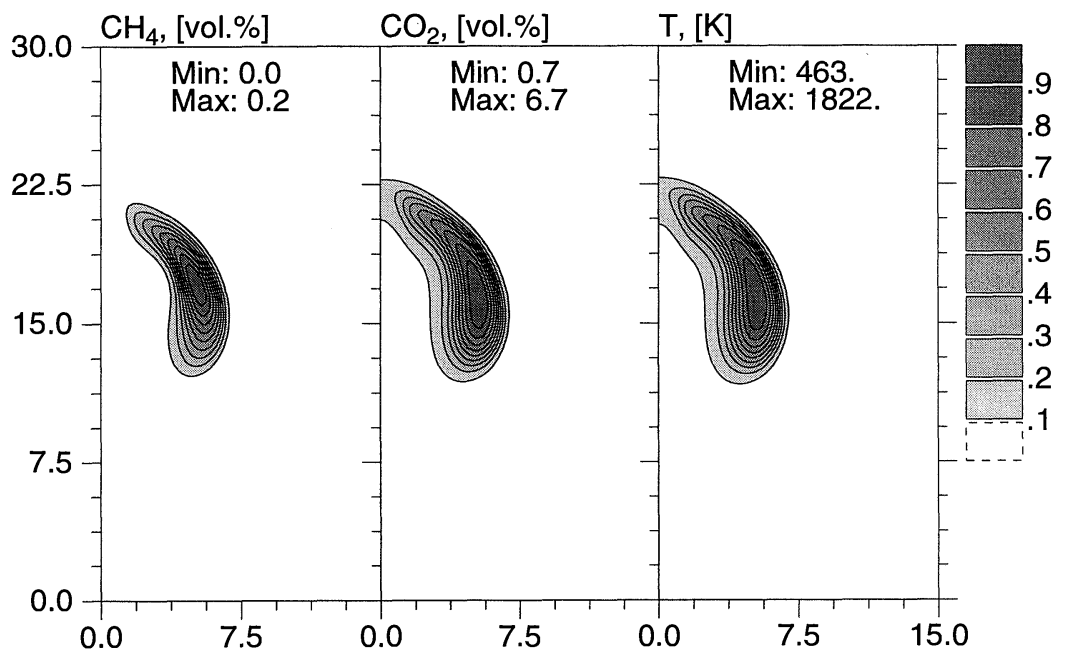

FIGURE 10. Stucture of the burning release at $t=3.5 t_{r}(2.5 \mathrm{~s})$ 


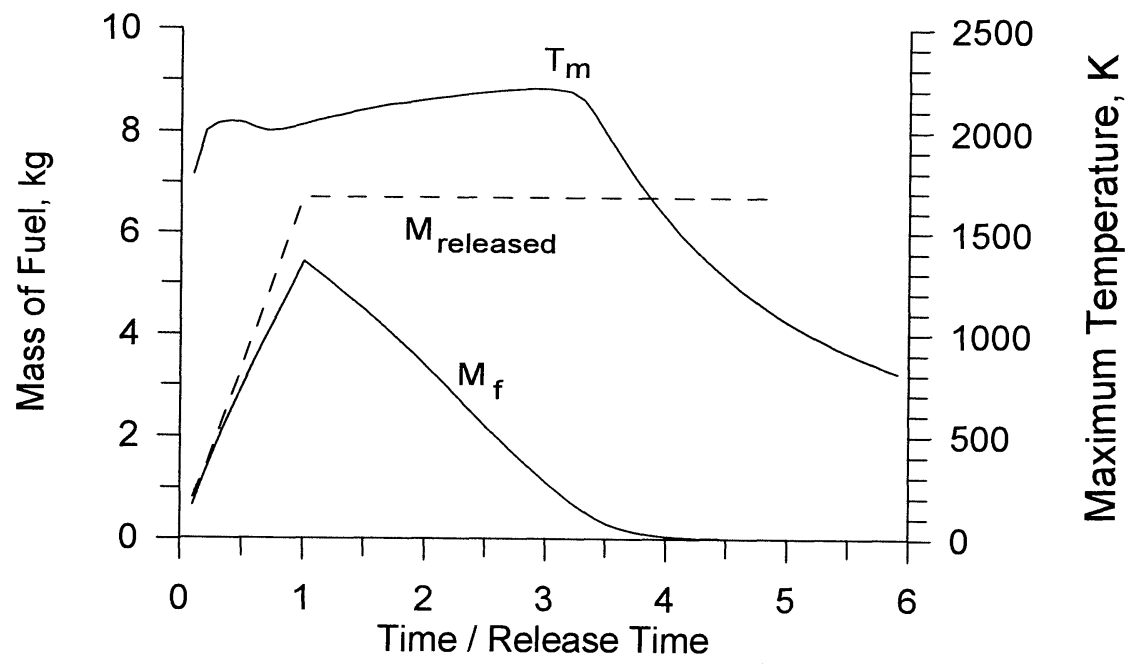

FIGURE 11. Time histories of fuel mass $M_{f}$ and maximum tempreature $T_{m}$ for the burning of the $10 \mathrm{~m}^{3}$ methane release. Dashed line shows the mass of methane injected into the atmosphere by the time $t$

\section{CONCLUSIONS}

Numerical modelling of formation, evolution and combustion of methane release is presented. It is shown that for finite-duration releases the internal stucture of the burning release is similar to that in a burning jet (at the initial stage of the evolution), it then transforms into a burning cloud (fireball). The spatial distributions of fuel and product concentrations as well as of the temperature and reaction rate are presented at different stages of the process. Calculations performed for different initial masses of fuel show that for a fixed release velocity the buoyancy effects reduce the burning time/release time ratio with increase in the gas volume. Namely, with increase in the gas volume from 10 to 10,000 $\mathrm{m}^{3}$ the ratio of the burning time to the release time decreases from approximately 5 to 1.5 . Comparison of the calculated size and duration of fireball with experimental data reveals a reasonable agreement. Further improvement of the model including implementation of radiation submodel is under way now.

This work has been carried out under the grant $G R / K 13486$ from the Engineering and Physical Sciences Research Council (EPSRC).

\section{REFERENCES}

1. McQuaid,J., "Industrial Fire Problems : an Overview", in 3rd Int. Symp. Fire Safety Science, eds. G. Cox, B. Langford, pp. 61-81, Elsevier, 1991.

2. Marshall, V., Major Chemical Hazards, Ellis Horwood, 1987. 
3. SFPE Handbook of Fire Protection Engineering, Nat. Fire Protection Association (NFPA), USA, Quincy, MA, 1988.

4. Bull, D.C., "Review of Large-Scale Explosion Experiments", Plant/Oper. Progress, 11:1, 33-40, 1992.

5. AIChE/CCPS, Guidelines for Evaluating the Characteristics of Vapor Cloud Explosions, Flash Fires, and BLEVEs, Amer. Inst. Chem. Engineers, New York, 1994.

6. Fay, J.A. and Lewis, D.H., "Unsteady Burning of Unconfined Fuel Vapour Clouds", 16th Symp. (Int.) on Combustion, The Combustion Institute, pp. 1397-1405, 1976.

7. Roberts, A.F.,"Thermal Radiation from Releases of LPG from Pressurised Storage", Fire Safety Journal, 4, 197-212, 1981/82.

8. Shield, S.R., "Model to Predict Radiant Heat and Blast Hazards from LPG BLEVEs. AIChE Symp. Ser., 89:295, 139-149, 1993.

9. Rosenblatt, M. and Hassig,P.J., "Numerical Simulation of the Combustion of an Unconfined LNG Vapor Cloud at a High Constant Burning Velocity", Comb. Sci. and Tech., 45, 245-259, 1986.

10. Makhviladze, G.M., Roberts, J.P., Yakush, S.E. and Davis. D., "Criterion for the Formation of a "Cloud-like" Release upon Depressurisation of a Gas Vessel", IChemE Symp. Series, 139, 97-112, 1995.

11. Magnussen, B.F. and Hjertager, B.H., "On the Mathematical Modelling of Turbulent Combustion with Special Emphasis on Soot Formation and Combustion", 16th Symp. (Int) on Combustion, Pittsburgh, PA, The Combustion Institute, pp. 711-729, 1976.

12. Vargaftic, N.B., Tables on the Thermophysical Properties of Liquids and Gases, J. Wiley, 1975.

13. Lapin, Yu.V. and Strelets, M.Kh., Internal Gas Mixtures Flows, Moscow, Nauka, 1989.

14. Makhviladze, G.M. and Melikhov, V.I., "A Numerical Method for Studying the Slow Combustion of Gases", Mathematical modelling, 1:6, 146-157, 1989.

15. Patankar, S.V., Numerical Heat Transfer and Fluid Flow, Hemisphere, 1980.

16. Roper, F., Arno, J. and Jaggers, H.C., "The Effect of Release Velocity and Geometry on Burning Times for Non-premixed Fuel Gas Clouds", Comb. Sci. and Tech., 78, 315-338, 1991.

17. Makhviladze, G.M., Selezniova, I.K. and Yakush, S.E., "Gaseous and Particulate Clouds in the Unbounded Atmosphere", in Mathematical Modelling and Applied Mathematics, eds. A.A. Samarskii and M.P. Sapagovas, pp. 279-287, Elsevier, North Holland, 1992.

18. Makhviladze, G.M., Roberts, J.P. and Yakush, S.E., "Modelling of Atmospheric Pollution by Explosions", Environmental Software, 10:2, 117-127, 1995. 